\title{
Seno, cosseno e tangente: uma atividade com os círculos de proporção de William Oughtred (1633) na formação de professores de matemática
}

Sine, cosine and tangent: an activity with the William Oughtred's circles of proportion (1633) in math teacher training

\author{
Verusca Batista Alves ${ }^{1}$ \\ Ana Carolina Costa Pereira ${ }^{2}$
}

\section{Resumo}

Nos estudos que relacionam a história da matemática com a formação de professores, há a construção de uma interface que propõe ações com base em instrumentos matemáticos históricos associados a um tratado que verse sobre eles. Um desses instrumentos são os círculos de proporção de William Oughtred (1574-1660), em The Circles of Proportion and the Horizontal Instrvment (1633). Com base na interface entre história e ensino de matemática, o artigo tem como objetivo apresentar algumas ações do movimento do pensamento de professores de matematica participantes de um curso de extensão, sobre o instrumento círculos de proporção. Para isso, foi feito um recorte da dissertação intitulada: Um estudo sobre os conhecimentos matemáticos mobilizados no manuseio do instrumento círculos de proporção de William Oughtred. Dos movimentos realizados no curso, o principal foi a busca do cosseno, somente por haver seno e tangente no instrumento. Com base nisso, pode-se dizer que os círculos de proporção são um instrumento potencialmente didático para o ensino de matemática, no que diz respeito à construção/dedução do cosseno a partir do seno e da tangente, buscando significar o conhecimento por meio do manuseio do instrumento.

Palavras chave: Círculos de proporção; Interface entre história e ensino de matemática; Formação continuada de professores de matemática.

\section{Abstract}

In studies that relate the history of mathematics to teacher education, there is the construction of an interface that proposes actions based on historical mathematical instruments associated with a treatise that talk about them. One of these instruments is William Oughtred's circles of proportion in The Circles of Proportion and the Horizontal Instrvment (1633). Based on the interface between history and mathematics teaching, the article aims to present some actions of the movement of thought of mathematics teachers participating in an extension course, about the instrument circles of proportion. Thereunto,

\footnotetext{
1 Instituto Federal de Educação, Ciência e Tecnologia do Ceará | veruscah.alves@gmail.com

2 Universidade Estadual do Ceará | carolina.pereira@uece.br
} 
this was done through the fragment of the dissertation: A study on the mathematical knowledge mobilized in the manipulation of William Oughtred's circles of proportion instrument. From the movements made in the course, the main one was the search for cosine, only because there is sine and tangent in the instrument. Based on this, it can be said that the circles of proportion are a potentially didactic instrument for the teaching of mathematics, with regard to the construction / deduction of the cosine from the sine and tangent, seeking to signify knowledge through manipulation of the instrument.

Keywords: Circles of Proportion; Interface between history and mathematics teaching; Continued Mathematics Teacher Training.

\section{Introdução}

A história da matemática, embora não tenha como objeto principal o ensino, é associada a pesquisas no campo da educação matemática por diversos estudiosos, tais como Mendes (2006, 2009), Chaquiam (2015) e Sousa (2016), especialmente, no que diz respeito a questões de ordem didática e metodológica. Nessa perspectiva, estudos, como os de Pereira e Saito (2019), buscam, na história da matemática, recursos que podem contribuir para o processo de construção de conhecimento matemático, caracterizando uma interface entre esses dois campos, a educação e a história da matemática.

Essa interface é definida como um conjunto de ações e produções que visam promover reflexões sobre o processo histórico relativo aos conhecimentos matemáticos, com o intuito de elaborar atividades didáticas que realizem essa articulação (SAITO; DIAS, 2013) e ela parte do diálogo entre o historiador e o educador matemático. Desse diálogo, emerge um recurso que se configura como um documento histórico e pode ser compreendido de diversas formas, tais como um tratado, um texto, um instrumento ou, ainda, fotos, imagens, vídeos, dentre outros (ALVES, 2019; ALBUQUERQUE, 2019; OLIVEIRA, 2019; PEREIRA; SAITO, 2019).

A partir disso, essa interface visa dois movimentos - o movimento do contexto no qual os conceitos foram desenvolvidos e o movimento do pensamento na formação do conceito matemático (SAITO; DIAS, 2013). O primeiro movimento citado se relaciona aos aspectos contextuais, historiográficos e epistemológicos (BELTRAN; SAITO; TRINDADE, 2014). Já o segundo enfoca, através do processo histórico, a formação do conceito matemático em si, pautando-se no objeto matemático em formação, que permite a construção de ideias lógicas que componham o movimento do pensamento (ALVES; PEREIRA, 2018).

Tomando como base os dois movimentos, uma terceira etapa é a confecção de atividades que busquem "[...] refletir o processo da produção do conhecimento que, dependendo da intencionalidade do educador, poderá ser orientada para diferentes propostas no ensino" (SAITO; DIAS, 2013, p. 101). Essas atividades são elaboradas a partir das potencialidades didáticas que emergem do processo dos dois movimentos.

No Brasil, os estudos, que envolvem a construção dessa interface, têm como objeto um instrumento matemático com suporte em um tratado que contenha sobre ele (ALVES, 2019; ALBUQUERQUE, 2019; OLIVEIRA, 2019; BATISTA, 2018; PEREIRA; SAITO, 2019; CASTILLO, 2016). Assim, dentre alguns instrumentos do século XVII, destacam-se os círculos de proporção, também conhecidos, em alguns estudos, como régua de cálculo circular e que estão inseridos no tratado The Circles of Proportion and the Horizontal Instrvment (1633) (ALVES; PEREIRA, 2018; ALVES, 2019). 
Associados à construção dessa interface, estudos, como os de Saito (2019), Pereira e Saito (2019) e Alves (2019), buscam articular, também, a formação de professores de matemática, promovendo uma reflexão sobre o desenvolvimento das práticas docentes em conformidade com as atuais necessidades educacionais. Desse modo, visando esse contexto, experiências de cursos de extensão se configuram como um diferencial formativo, no que diz respeito à ampliação curricular do professor de matemática.

Com isso, aqui, é apresentado um recorte da dissertação intitulada: Um estudo sobre os conhecimentos matemáticos mobilizados no manuseio do instrumento círculos de proporção de William Oughtred, que teve como objeto de estudo os círculos de proporção e se delineou para conhecer como os conhecimentos matemáticos, incorporados nos círculos de proporção, são mobilizados no estudo de seu manuseio, em uma interface entre a história e o ensino de matemática.

Dentre alguns conhecimentos matemáticos que emergiram na discussão, a construção do conceito de seno, cosseno e tangente foi um deles. Dessa maneira, a partir de um curso de extensão aplicado a alunos do mestrado profissional em matemática (PROFMAT), da Universidade Estadual do Ceará (UECE), este artigo visa apresentar algumas ações do movimento do pensamento dos professores participantes do curso, no estudo dos círculos de proporção, em específico, os conteúdos de seno, cosseno e tangente.

\section{Caminho metodológico e aporte teórico}

De modo primário, pode-se dizer que, neste estudo, elencaram-se, como base teórica, as pesquisas que buscam desenvolver uma interface entre história e ensino de matemática (SAITO; DIAS, 2013; PEREIRA; SAITO, 2019) e a Atividade Orientadora de Ensino (MOURA et al., 2016).

De caráter qualitativo, entende-se esta pesquisa em uma concepção multirreferencial, concebida por Borba (1998) como "bricolagem", que se refere "à capacidade de empregar abordagens de pesquisa e construtos teóricos múltiplos" (KINCHELOE; BERRY, 2007, p. 10), pois se concorda com Rodrigues et al. (2016, p. 970) de que "[...] instalou-se a necessidade premente de se refletir acerca de novas possibilidades investigativas, considerando-se a constituição de caminhos teórico-metodológicos alternativos".

Com relação à demarcação dos instrumentos de coleta e registro de dados, optou-se por observação; relatórios (registro dos participantes); gravação de áudios e vídeos e fotos (ANDRÉ, 2013). Esses instrumentos foram, convenientemente, escolhidos, já que, a partir deles, é que se pode obter as características do grupo que se está estudando. Neste artigo, é apresentada a discussão dos dados contidos no relatório, em específico, sobre a temática de seno, cosseno e tangente.

Todos os instrumentos de coleta de dados aplicados foram autorizados pelos participantes e pelo Comitê de Ética do Instituto Federal de Educação, Ciência e Tecnologia do Ceará (IFCE), instituição de origem, e da Universidade Estadual do Ceará (UECE), 
instituição coparticipante, a serem analisados e publicados através do Termo de Consentimento Livre e Esclarecido - TCLE e do parecer de ambas as instituições ${ }^{3}$.

No que diz respeito ao processo de construção de uma atividade para a formação de professores, inicialmente, é preciso compreender o conceito de atividade em si. Para isso, segue-se, aqui, a Atividade Orientadora de Ensino (AOE), defendida por Moura et al (2016), fundamentada em Leontiev (2009), em que se compreende o conceito de atividade "[...] como uma unidade de análise do desenvolvimento humano e as principais relações que o caracterizam, [que] pode orientar a organização do ensino" (MOURA et al. 2016, p. 109).

$\mathrm{Na} A O E$, tanto o professor quanto o aluno são sujeitos em atividade e portadores de conhecimentos. Em relação ao professor, ele realiza a atividade de ensino, que "[...] tem objetivos (individuais e coletivos), define ações para atingi-los e, conforme as condições reais, executa as operações [...] que sustentam as ações" (MOURA et al., 2016, p. 116). Já o aluno realiza a atividade de estudo, que, levando em consideração os pressupostos vigotskianos, Davidov (1988) apud Moura et al. (2016) explicita em três conceitos importantes, que compõem essa atividade de estudo: tarefa de estudo, ações de estudo e ações de autoavaliação e regulação.

A tarefa de estudo "[...] tem por finalidade a transformação do próprio sujeito, transformação essa que não é possível fora das ações objetais que este realiza" e ela está associada à generalização teórica do conhecimento (MOURA, et al, 2016, p. 97). Já as ações de estudo proporcionam ao estudante condições individuais para construir relações gerais, identificar conceitos principais e estruturar relações (MOURA et al., 2016). E a ação de autoavaliação e regulação está relacionada à capacidade do estudante de avaliar suas próprias ações, no início, no percurso e no resultado de seu trabalho, no decorrer da atividade (MOURA et al., 2016).

Então, a atividade de estudo, mediada pela ação docente, permite que o aluno "[...] se aproprie de conceitos historicamente construídos, de forma sistematizada e intencional [...]" (MOURA et al., 2016, p. 98). Para isso, é necessário, primeiramente, definir o objetivo dessa atividade. Esse objetivo deve ser estruturado de modo a

[...] possibilitar aos estudantes a apropriação dos conhecimentos e das experiências histórico-culturais da humanidade. Entretanto, dada a vastíssima experiência da humanidade, mais importante do que ensinar todo e qualquer conhecimento, o que seria tarefa impossível, é ensinar ao estudante um modo de ação generalizada de acesso, utilização e criação do conhecimento, o que torna possível ao considerar-se a formação do pensamento teórico (MOURA et al., 2016, p. 112).

Com isso, entende-se que a Atividade Orientadora de Ensino (AOE) articula objetivos, ações e operações que organizam o processo de ensino e defende que isso reflete na própria necessidade do aluno de se apropriar do conceito, permitindo, assim, um processo de aprendizagem. Há que se destacar que, na $A O E$, a atividade de ensino e a atividade e aprendizagem são separadas somente para fins de explicação, pois ambas precisam concordar para se concretizar.

\footnotetext{
${ }^{3}$ Parecer do CEP do Instituto Federal de Educação, Ciência e Tecnologia do Ceará, sob n- 3.207.189 e CAAE: 08817119.5.0000.5589. E parecer do CEP da Universidade Estadual do Ceará, sob nํ 3.285.573 e CAAE: 08817119.5.3001.5534.
} 
Desse modo, como base para a elaboração de uma atividade para a formação de professores, tomaram-se as etapas inter-relacionadas de Saito e Dias (2013), que orientam o desenvolvimento de uma atividade na interface entre a história e o ensino de matemática, que são: 1) tratamento didático; 2) intencionalidade e plano de ação; 3) desenvolvimento. Tais etapas são descritas nas seções seguintes.

A respeito do tratamento didático, para Saito e Dias (2013, p. 102), ele consiste em "[...] tratar o texto de acordo com os propósitos didáticos, sem invadir o texto". Ou seja, é preciso fazer a adaptação do material, de acordo com a finalidade da atividade proposta, no entanto, sem descaracterizar esse material.

Assim, o tratamento consistiu na tradução do texto para o português brasileiro, já que o tratado The Circles of Proportion (1633), de William Oughtred, está no idioma inglês, do século XVII. Além da tradução, foi necessária a adaptação da escrita do texto, visando facilitar a leitura e a compreensão. Saito e Dias (2013, p. 101) defendem que um tratamento adequado dos documentos, "[...] associada a tendências didático-pedagógicas da Educação Matemática, pode conduzir a uma profícua articulação entre a história e ensino de matemática".

Além disso, cabe ressaltar que esse tratamento deve ser realizado com um objetivo didático, uma vez que a finalidade é o ensino. Para essa atividade de ensino, escolheram-se os capítulos 1 e 2 do documento The Circles of Proportion (1633), que tratam da descrição e da manipulação do instrumento círculos de proporção.

Com relação ao segundo ponto, a intencionalidade e o plano de ação, o professor/pesquisador volta seu olhar aos propósitos do processo da sua ação docente, ou seja, a atividade de ensino, buscando relacionar a organização dessa atividade com as potencialidades didáticas pertinentes. Também, deve-se estabelecer o objetivo e definir os detalhes referentes ao seu desenvolvimento, tais como uma aula, oficina ou minicurso; o tempo; o local; o público-alvo, dentre outros de ordem organizacional.

Para esta pesquisa, optou-se por um curso de extensão universitária ${ }^{4}$, cujo título foi "Estudando os conhecimentos matemáticos incorporados no manuseio dos círculos de proporção de William Oughtred". Ele ocorreu aos sábados, nos dias 02/02/2019 e 09/02/2019, de 8h às 17h, com intervalo para almoço, totalizando uma carga horária de 16h/a presenciais e foi ministrado no Laboratório de Matemática e Ensino ${ }^{5}$, da Universidade Estadual do Ceará, Campus Itaperi, em Fortaleza.

O público-alvo, para essa aplicação, foram alunos do Programa de Mestrado Profissional em Matemática (PROFMAT), da Universidade Estadual do Ceará (UECE), convidados a participar, em período extracurricular à sua formação, que tivessem interesse e disponibilidade de estar presentes em todos os dias do curso. Ao todo, ofertaram-se 12 vagas, considerando a técnica de observação escolhida para a coleta de dados.

\footnotetext{
${ }^{4}$ A realização do curso foi em parceria com o Grupo de Pesquisa em Educação e História da Matemática (GPEHM) (http://gpehm.blogspot.com/) e da coordenadoria do curso de Licenciatura de Matemática da UECE, que disponibilizaram o espaço físico no qual ele ocorreu. $O$ desenvolvimento do curso teve base no projeto Guarda-Chuva do Programa de Formação Docente (PFD) do GPEHM.

${ }^{5}$ O nome oficial é Laboratório de Matemática e Ensino Professor Bernardo Rodrigues Torres (LAbMAtEn/UECE), mais conhecido como Laboratório de Matemática e Ensino, oficializado em 1998 (PEREIRA; VASCONCELOS, 2014).
} 
Seguindo os pressupostos da interface, a etapa da intencionalidade e o plano de ação são explicados por Pereira e Saito (2019, p. 349):

Nesta etapa, o que está em questão é o olhar do pesquisador para a potencialidade didática no intuito de articulá-la com o ensino de algum conceito matemático. Assim, uma vez delineada a intenção pela qual atividade foi elaborada, parte-se para o plano de ação, que consiste em planejar a aplicação das atividades. É por meio deste planejamento que a ação é orientada tendo em vista a prática em sala de aula.

Com base nisso, o desenvolvimento das aulas foi sistematizado em quatro momentos, nos quais, em cada um, foi definido um objetivo - Momento 1: Conhecer os círculos de proporção de William Oughtred a partir da leitura da descrição do instrumento, contida na obra The Circles of Proportion and the Horizontal Instrvment (1633); Momento 2: Compreender o processo de manipulação do instrumento círculos de proporção de William Oughtred, através de situações práticas; Momentos 3 e 4: Identificar os elementos matemáticos presentes no manuseio do instrumento com suporte à leitura do excerto (ALVES, 2019).

Além disso, o plano de ação sugeriu uma organização de materiais e aplicação, conforme Alves (2019, p. 89):

1) Atividade: chama-se de atividade a ação tomada pelos participantes, orientada pelo docente, que foi dividida em quatro momentos. 2) Momentos: é o conjunto de ações, diálogos e tarefas realizados pelos grupos participantes, compostos pelos seguintes itens: a) Ficha de Relatórios: destinado aos grupos do curso. Constitui-se como parte seguinte a cada momento proposto, no qual os participantes, em forma de um relatório, produziram anotações referentes às ações que eles realizaram. Cada momento, teve um relatório próprio. b) Cartão de Recurso: destinado aos grupos do curso, é o material histórico, já feito o tratamento didático, que foi utilizado nos momentos. c) Cartão Guia: destinado aos grupos do curso, é um guia que contém a explicação do momento proposto e que serviu de base para a construção do relatório. 3) Cartão de Hipóteses: destinado à docente pesquisadora, são as hipóteses de ordem matemática, textual, material que foram levantadas e investigadas no decorrer do curso de extensão e da análise dos dados coletados. 4) Bloco de Observações: destinado à professora pesquisadora e à observadora. É um bloco no qual são feitas anotações no decorrer da atividade do curso, visando complementar outros materiais de coleta de dados.

Também, foi pré-estabelecida a organização dos participantes no ambiente, que consistiu em dividi-los em equipes de, no máximo, 3 integrantes. A opção pelo trabalho coletivo "[...] ancora o desenvolvimento das funções psíquicas superiores, ao configurar-se no espaço entre a atividade interpsíquica e a atividade intrapsíquica" (MOURA et al., 2016, p. 101). Assim, para caracterizar uma atividade de aprendizagem coletiva, entende-se que ela precisa conter:

[...] a repartição das ações e das operações iniciais, segundo as condições da transformação comum do modelo construído no momento da atividade; a troca de modos de ação, determinada pela necessidade de 
introduzir diferentes modelos de ação, como meio de transformação comum do modelo; a compreensão mútua, permitindo obter uma relação entre, de um lado, a própria ação e seu resultado e, de outro, as ações de um dos participantes em relação a outro; a comunicação, assegurando a repartição, a troca e a compreensão mútua; o planejamento das ações individuais, levando em conta as ações dos parceiros com vistas a obter um resultado comum; a reflexão, permitindo ultrapassar os limites das ações individuais em relação ao esquema geral da atividade (assim, é graças à reflexão que se estabelece uma atitude crítica dos participantes com relação às suas ações, a fim de conseguir transformá-las, em função de seu conteúdo e da forma do trabalho em comum) (RUBTSOV, 1996, p. 136, grifo nosso).

Seguindo o modelo de Rubtsov (1996), fez-se a separação das funções de cada participante nos grupos formados da seguinte maneira:

Facilitador - Certifica-se de que todos obtenham a ajuda de que precisam para realizar a tarefa; é responsável por procurar respostas para as perguntas dentro do grupo; o professor só é consultado apenas se ninguém do grupo puder ajudar. Verificador - Certifica-se de que todo mundo tenha completado seu relatório individual. Relator - É responsável por organizar o relatório do grupo e sua apresentação para a turma. Gerenciador de Materiais (monitor) - É responsável por obter materiais e recursos e por retirá-los adequadamente. Controlador de tempo - É responsável por regular o tempo da atividade proposta. Harmonizador É responsável por resolver os possíveis conflitos que venham a existir no grupo (COHEN; LOTAN, 2017, p. 112, grifo nosso).

É necessário destacar que haviam seis funções a serem executadas e, por isso, cada participante poderia assumir até duas funções. Determinados os objetivos e traçado o plano, segue-se para o desenvolvimento que se refere à realização da atividade em si, descrito no tópico sobre a atividade.

\section{A Trigonometria nos círculos de proporção e a atividade}

William Oughtred (1574-1660) ${ }^{6}$ foi um ministro anglicano que dedicou parte de sua vida ao estudo das matemáticas. Dentre suas ações, ele escreveu e publicou diversas obras sobre vários tópicos matemáticos. Uma delas foi The Circles of Proportion and the Horizontal Instrvment (1633) (figura 1), que englobava diversos conteúdos matemáticos agregados ao manuseio de um instrumento.

Como autor, William Oughtred buscou contribuir para o desenvolvimento das matemáticas e uma de suas principais ações foi o uso de símbolos para facilitar a leitura matemática. Dentre eles, em Oughtred (1633), ele se utiliza de $s$ para se referir ao seno, $t$ para tangente e s co para seno do completo, que hoje se entende por cosseno.

\footnotetext{
${ }^{6}$ Para conhecer mais sobre William Oughtred, vide Cajori (1916).
} 


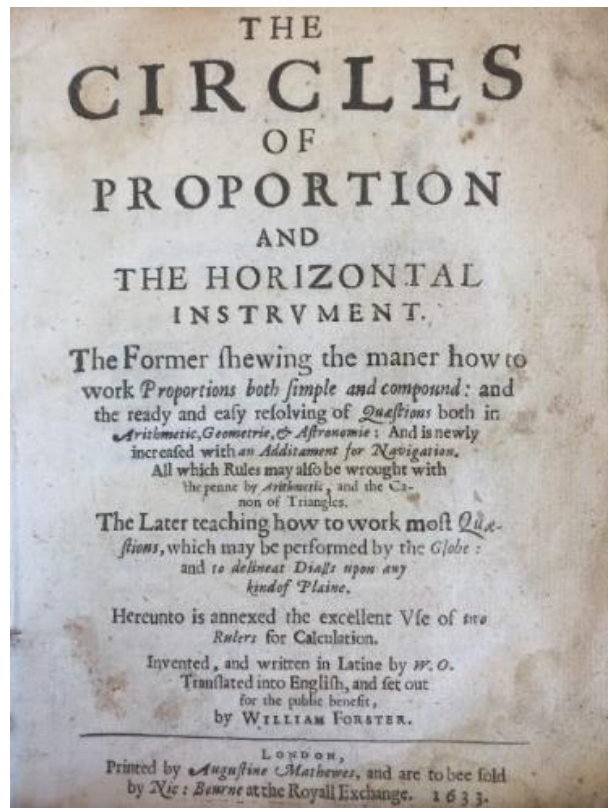

Figura 1: Frontispício de The Circles of Proportion... (1633). Fonte:

Oughtred (1633, frontispício).

Nessa obra, William Oughtred, também, apresenta um instrumento circular que possui dois lados (frente e verso) (figura 2). "De um lado, como se fosse a planície do horizonte, é delineada a projeção da esfera. Do outro lado, existem vários tipos de círculos, divididos depois de várias maneiras, junto com um indicador" (OUGHTRED, 1633, p. 1, tradução nossa).
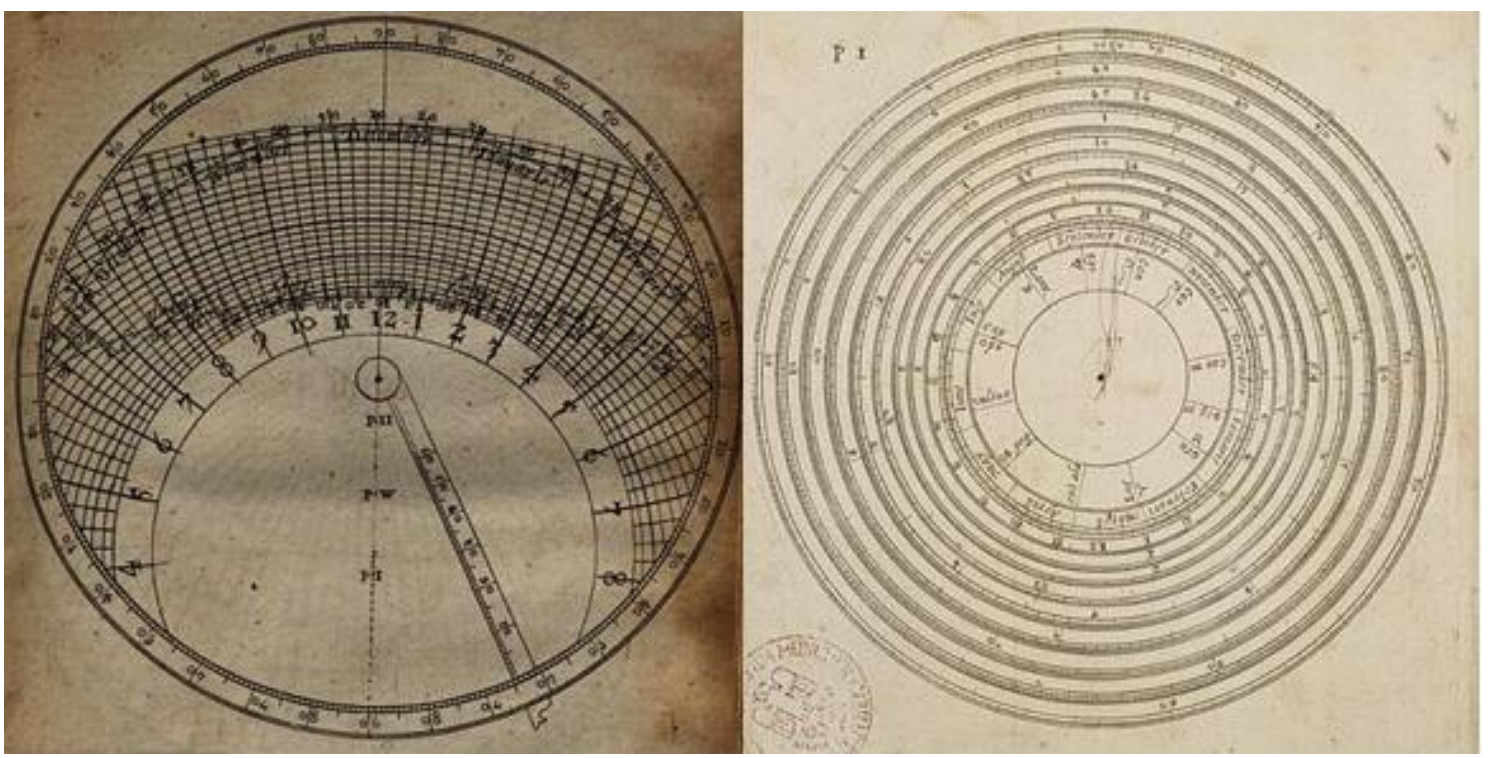

Figura 2: Instrumento horizontal (esquerda) e círculos de proporção (direita). Fonte: Oughtred (1633, p. P1, P195).

A respeito dos círculos de proporção, Oughtred (1633) ilustra, para o leitor, que o instrumento possui oito círculos graduados de várias formas:

O primeiro, ou círculo mais externo é de senos, de 5 graus e 45 minutos aproximadamente, até quase 90 graus. [...] O segundo círculo é de tangentes de 5 graus e 45 minutos aproximadamente, até 45 graus. [...] 0 terceiro círculo é de tangentes de 45 graus até 84 graus e 15. [...] O sexto 
círculo é de tangentes de 84 graus até aproximadamente 89 graus e 25 minutos. [...] O sétimo círculo é de tangentes de aproximadamente 35 minutos até 6 graus. [...] O oitavo círculo é de senos de aproximadamente 35 minutos até 6 graus. [...] O quarto círculo é de Números Desiguais, que são anotados com os números $2,3,4,5,6,7,8,9$, 1. Quer você os compreenda como números únicos, dezenas, centenas ou milhares, etc. [...] O quinto círculo é de Números Iguais, que são anotados com os números 1, 2, 3, 4, 5, 6, 7, 8, 9, 0. [...] (OUGHTRED, 1633, p. 2-4, tradução nossa).

Como se nota, na explicação de Oughtred (1633), há duas escalas graduadas com seno, quatro com tangente e duas que ele nomeia de números iguais e desiguais. Além disso, há um par de indicadores que são utilizados no manuseio do instrumento, que ele chama de braço antecedente e braço consequente.

Para manipular os círculos de proporção, ele instrui que se deve girar os indicadores para obter os resultados das operações da seguinte forma:

Abra os braços do Instrumento à distância do primeiro e do segundo número: depois traga o braço antecedente, ou aquele que permaneceu sobre o primeiro número até o terceiro, e assim o braço consequente, mantendo a mesma abertura, mostrará o quarto número procurado (OUGHTRED, 1633, p. 5, tradução nossa).

Seguindo a explicação, os cálculos realizados pelos círculos de proporção se baseiam, principalmente, no uso da proporção e dos logaritmos, de forma associada. Com isso, a principal característica do manuseio dos indicadores é, justamente, manter a proporção entre os braços para obter os valores.

Dentre as possibilidades de manusear o instrumento, podem-se definir duas: a primeira está relacionada a indicar valores, conforme uma tabela (ALVES, 2019). Assim, quando se quer saber o valor do seno ou tangente de qualquer ângulo, basta posicionar um dos indicadores no ângulo correspondente ao que se quer obter. A segunda utiliza os dois indicadores para operar por meio da proporção (ALVES, 2019).

Sobre a primeira forma de manuseio, Oughtred (1633) exemplifica dizendo que "seno de 23030' será encontrado 3987; e o seno de seu complemento 9171, [...] a tangente de 23030' encontrada será 4348" (OUGHTRED, 1633, p. 3, tradução nossa). Note que os valores, citados por Oughtred (1633), ao serem divididos por 10000, o raio correspondente ao período, tem-se os valores que seriam obtidos em uma calculadora moderna, ou seja, o seno de $23^{\circ} 30^{\prime}$ vale aproximadamente 0,3987 ; o seno de seu complemento ou cosseno, 0,9171 e a tangente, 0,4348.

Após essa breve explicação a respeito dos círculos de proporção, sabe-se que há diversos conhecimentos matemáticos incorporados. Com isso, aplicou-se um curso de extensão universitária visando ressignificar alguns conceitos matemáticos a partir do manuseio do instrumento.

A atividade proposta contou com quatro momentos inter-relacionados, dentre os quais, o segundo propunha compreender o processo de manipulação do instrumento através de situações práticas. A respeito desse segundo momento, foi entregue um excerto histórico (quadro 1), que continha dois teoremas matemáticos, uma explicação de como manipular os indicadores e um exemplo para cada situação proposta em cada operação. 


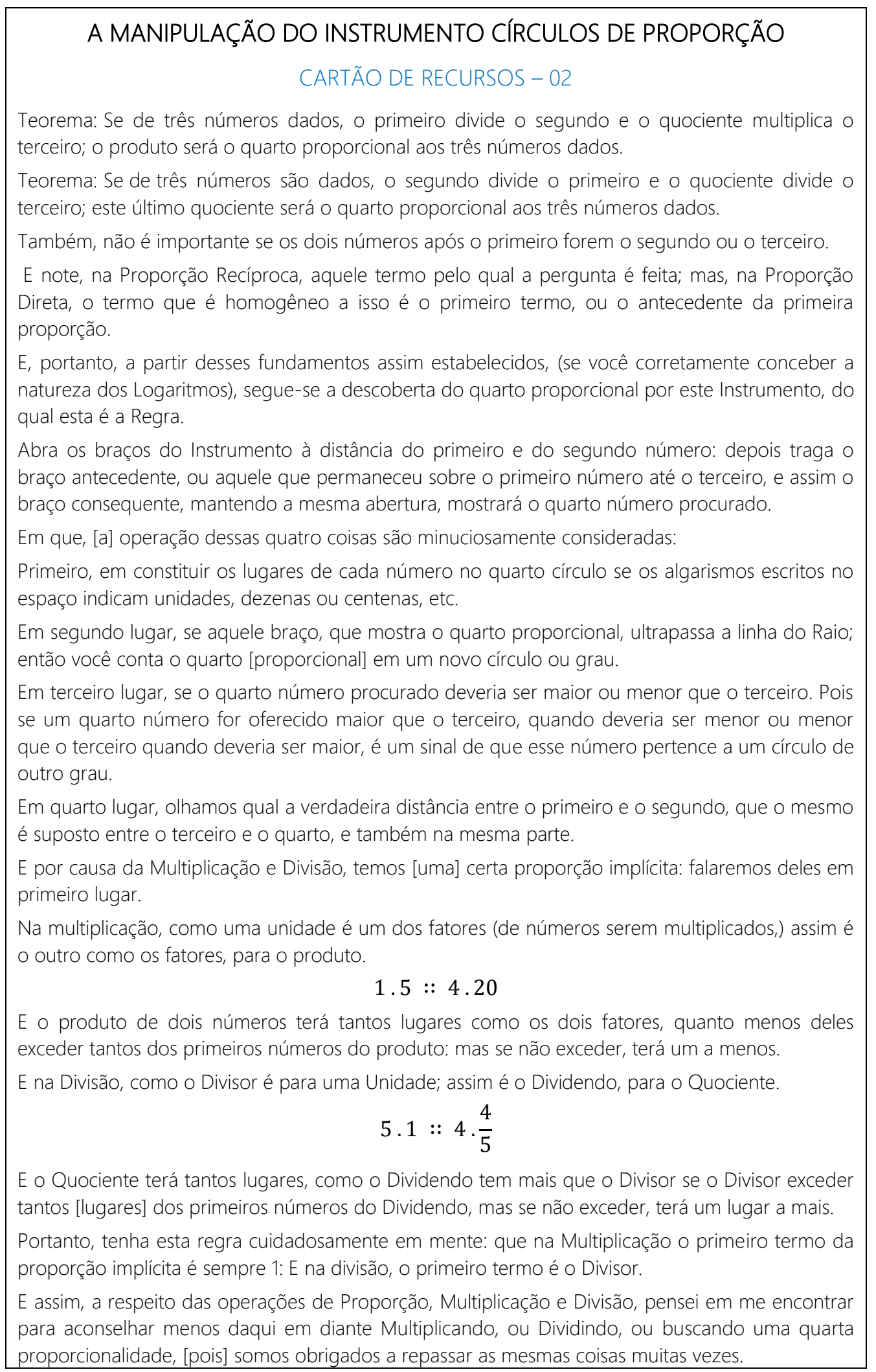

Quadro 1: Excerto da obra, capítulo 2. Fonte: Oughtred (1633, p. 5-7, tradução nossa). 
É importante ressaltar que, antes desse momento, os participantes receberam outro excerto histórico que continha a respeito da descrição dos círculos de proporção e o instrumento reconstruído ${ }^{7}$ (figura 3) para que eles pudessem conhecer o aparato.

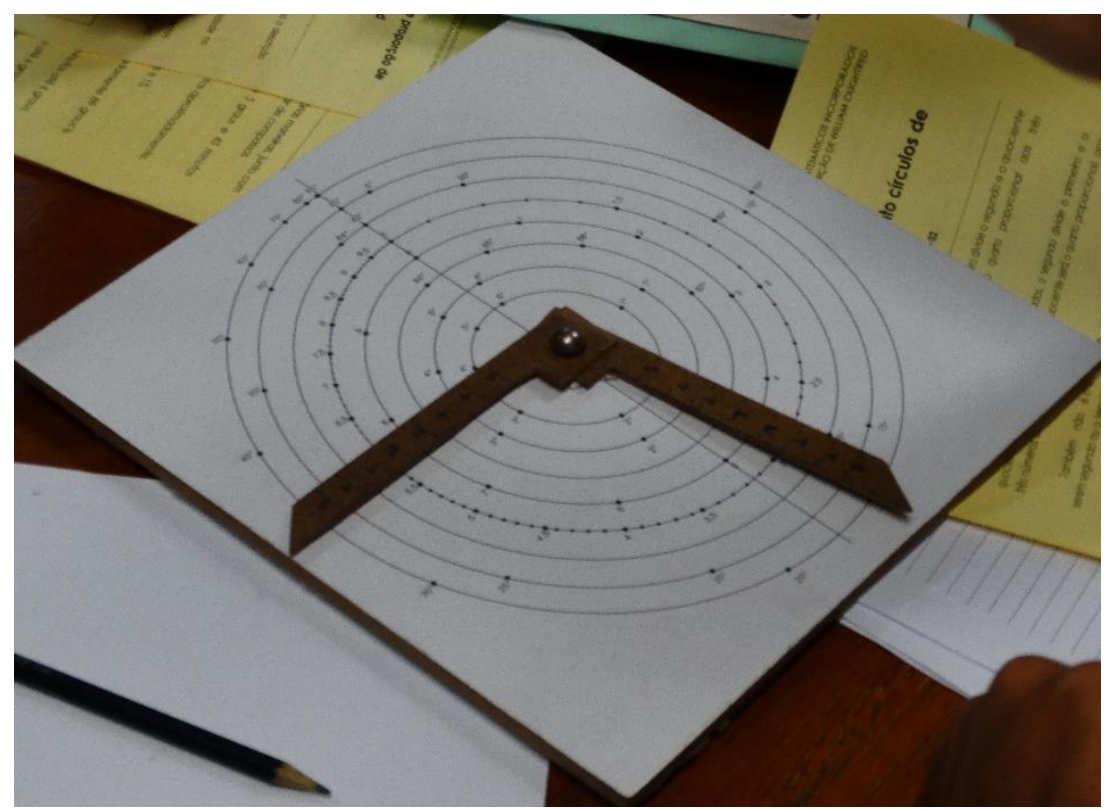

Figura 3 - Círculos de proporção reconstruídos. Fonte: Alves (2018; 2019).

Os participantes foram orientados a ler o excerto e manipular o instrumento, buscando compreender a respeito dos conhecimentos incorporados em seu manuseio. Além disso, eles deveriam produzir um relatório a partir dessa tarefa, que expressasse suas compreensões.

As primeiras tentativas de manuseio do instrumento foram relacionadas a testar valores. Conforme Oughtred (1633) apresenta os círculos de proporção, contendo escalas de seno e tangente, os participantes buscaram, inicialmente, testar alguns valores para validar o instrumento. Essa ação pode ser notada na fala do Grupo 4 - "Fizemos testes com os valores de senos e tangentes de ângulos notáveis e obtivemos o valor esperado para o seno de $30^{\circ}$ e tangente de $45^{\circ}$."

Esse movimento de testar os valores foi uma ação esperada, uma vez que, a partir disso, eles estavam em busca de associar os conhecimentos matemáticos já conhecidos ao instrumento que eles estavam estudando. Isso caracteriza o movimento do pensamento de Saito e Dias (2013) e Pereira e Saito (2019).

Em relação à divisão das escalas presentes nos círculos de proporção, esperava-se que os participantes se questionassem a respeito da quantidade de escalas destinadas ao seno e à tangente, como, por exemplo, por que há duas escalas de seno e quatro de tangente? Sobre isso, apenas o Grupo 4 relatou que essa quantidade de círculos, para seno e para tangente, tem relação com os ângulos neles graduados.

O Grupo 4 diz - "[...] compreendemos que o $6^{\circ}, 7^{\circ}$, e $8^{\circ}$ círculos complementam os círculos maiores com os ângulos não contemplados por eles". No entanto, eles não

\footnotetext{
${ }^{7}$ Para conhecer sobre a reconstrução feita através do software GeoGebra, vide Alves e Pereira (2019).
} 
explicitam por que se teve a necessidade de se utilizar de dois círculos para graduar a escala de seno e quatro para a de tangente, ao invés de se utilizar apenas um para cada.

Além das escalas de seno e tangente, somente o Grupo 1 questionou, então, a falta de uma escala que correspondesse aos cossenos. Sobre isso, entende-se que esse questionamento pode ter uma base na própria estrutura de ensino. Quando se leciona a respeito das razões trigonométricas, normalmente, as três, seno, cosseno e tangente, são associadas.

O Grupo 1, em seguida, relatou que não seria, portanto, necessária uma escala de cosseno, uma vez que "[...] os valores das razões de cosseno podem ser obtidos realizando a divisão entre os valores obtidos da razão seno e tangente, de acordo com os indicadores". Isso reforça a compreensão de que a estrutura de como se ensina sobre as razões trigonométricas pode ter influenciado nesse pensamento, pois elas seguem uma ordem em que primeiro se tem o seno, em seguida, o cosseno e, por fim, obtém-se a tangente. Também, apresentam as relações que umas têm com as outras e, dentre elas, a tangente é uma razão entre o seno e o cosseno. Com isso, o movimento natural é conhecer o cosseno após o seno e antes da tangente.

Percebe-se que essa a compreensão do seno, cosseno e tangente está mais relacionada às três fórmulas, do que ao próprio significado em si que essas relações têm. Ao buscarem pelo cosseno, que se considera uma ação natural, também, estão realizando o movimento do pensamento de Saito e Dias (2013) e Pereira e Saito (2019).

Fundamentado nisso, identifica-se uma potencialidade didática para o ensino de matemática, que é a construção/dedução do cosseno a partir do seno e da tangente, buscando significar esse conhecimento através do estudo do manuseio dos círculos de proporção.

\section{Conclusões}

No Brasil, pesquisas que visam uma interface entre a história e o ensino de matemática, pautadas em uma historiografia atualizada ${ }^{8}$, buscam promover uma reflexão sobre a ação docente no processo de ensino de matemática (SAITO; DIAS, 2013; PEREIRA, SAITO, 2019; SAITO, 2019).

Desse modo, compreendendo que a história da matemática fornece uma rede de conhecimentos que podem auxiliar nos processos de ensino de conteúdos matemáticos, a ação principal deve se configurar, primeiramente, na formação do professor de matemática.

Com isso, a partir dos estudos de Saito e Dias (2013) e Pereira e Saito (2019), tomando como base a construção de uma interface entre a história e o ensino de matemática, os estudos iniciais já foram realizados, no que diz respeito ao instrumento círculos de proporção de William Oughtred.

Vale ressaltar que, ainda, há muito o que ser explorado nos círculos de proporção, visto que, aqui, abordaram-se somente três conceitos que estão incorporados no instrumento. Mesmo assim, entende-se que uma próxima etapa está ancorada na produção de atividades didáticas, agora com o público-alvo voltado à educação básica.

\footnotetext{
${ }^{8}$ A respeito das perspectivas historiográficas, vide Saito (2015); Beltran, Saito e Trindade (2014); Bromberg e Saito (2010).
} 


\section{Referências}

ALBUQUERQUE, S. M. de. Um estudo sobre a articulação entre a multiplicação contida no Traité de Gerbert (1843) e o ensino na formação de professores de matemática. 2019. 145 f. Dissertação (Mestrado em Ensino de Ciências e Matemática) - Instituto Federal do Ceará, Fortaleza, 2019.

ALVES, V. B. Um estudo sobre os conhecimentos matemáticos mobilizados no manuseio do instrumento círculos de proporção de William Oughtred. 2019. 153 f. Dissertação (Mestrado em Ensino de Ciências e Matemática) - Instituto Federal do Ceará, Fortaleza, 2019.

ALVES, V. B.; PEREIRA, A. C. C. A reconstrução dos círculos de proporção no geogebra como uma atividade para a mobilização de conhecimentos matemáticos. Revista história da matemática para professores, v. 5, n. 1, p. 19-28, 2019. Disponível em:

http://www.rhmp.com.br/index/index.php/rhmp/article/view/69. Acesso em: 13 dez. 2019.

ALVES, V. B.; PEREIRA, A. C. C. O instrumento "círculos de proporção" exposto na obra de William Oughtred (1633): um elemento na interface entre história e ensino de matemática. Revista de Produção Discente em Educação Matemática, São Paulo, v. 7, n. 2, p.89-108, 2018. Disponível em: https://revistas.pucsp.br/pdemat/article/view/39043. Acesso em: 13 dez. 2019.

ANDRÉ, M. E. D. A. de. Etnografia da prática escolar. Campinas: Papirus, 2013.

BATISTA, A. N. de S. Um estudo sobre os conhecimentos matemáticos incorporados e mobilizados na construção e no uso da balhestilha, inserida no documento Chronographia, Reportorio dos Tempos..., aplicado na formação de professores. 2018. 114f. Dissertação (Mestrado em Ensino de Ciências e Matemática) - Instituto Federal do Ceará, Fortaleza, 2018.

BELTRAN, M. H. R.; SAITO, F.; TRINDADE, L. dos S. P. História da Ciência para a formação de professores. São Paulo: Ed. Livraria da Física, 2014.

BORBA, S. da C.. Aspectos do conceito de multirreferencialidade nas ciências e nos espaços de formação. In: BORBA, Sérgio da Costa (Org.). Reflexões em torno da abordagem multirreferencial. São Carlos: EdUFSCar, 1998.

BROMBERG, C.; SAITO, F. A história da matemática e a história da ciência. In: BELTRAN, M. H. R.; SAITO, F.; TRINDADE, L. dos S. P. História da ciência: tópicos atuais. São Paulo: Livraria da Física, 2010. p. 47-71.

COHEN, E. G.; LOTAN, R. A. Planejando o trabalho em grupo. 3. ed. Porto Alegre: Penso, 2017. Tradução de: Luís Fernando Marques Dorvillé, Mila Molina Carneiro, Paula Márcia Schmaltz Ferreira Rozin.

CAJORI, F. William Oughtred: a great seventeenth-century teacher of mathematics. Chicago: The Open Court Publishing Company, 1916.

CASTILLO, A. R. M. Um estudo sobre os conhecimentos matemáticos incorporados e mobilizados na construção e no uso do báculo (cross-staff) em A Boke Named Tectonicon de Leonard Digges. 2016. 121 f. Tese (Doutorado em Educação Matemática) - Pontifícia Universidade Católica de São Paulo, São Paulo, 2016. Disponível em: https://tede2.pucsp.br/handle/handle/18982. Acesso em: 19 dez. 2019. 
CHAQUIAM, M. História da matemática em sala de aula: proposta para integração aos conteúdos matemáticos. São Paulo: Livraria da Física, 2015.

KINCHELOE, J. L.; BERRY, Kathleen. S. Pesquisa em educação: conceituando a bricolagem. Porto Alegre: Artmed, 2007.

LEONTIEV, A. N.. Actividade, Consciência e Personalidade. The Marxists Internet Archive, 1978. Tradução de: Maria Silvia Cintra Martins, 2009.

MENDES, I. A. Investigação histórica no ensino da Matemática. Rio de Janeiro: Ciência Moderna, 2009.

MENDES, I. A. Matemática e investigação na sala de aula: tecendo redes cognitivas na aprendizagem. Natal: Flecha do Tempo, 2006.

MOURA, M. O. de et al. (Org.). A Atividade Orientadora de Ensino como Unidade entre Ensino e Aprendizagem. In: MOURA, Manoel Oriosvaldo de (Org.). A atividade pedagógica na teoria histórico-cultural. 2. ed. Campinas: Autores Associados, 2016. Cap. 4. p. 93-125.

OLIVEIRA, F. W. S. Sobre os conhecimentos geométricos incorporados na construção e no uso do instrumento jacente no plano de Pedro Nunes (1502-1578) na formação do professor de matemática. 2019. 200f. Dissertação (Mestrado em Ensino de Ciências e Matemática) Instituto Federal do Ceará, Fortaleza, 2019.

OUGHTRED, W. The Circles of Proportion and the Horizontal Instrvment. London: Augustine Mathewes, 1633.

PEREIRA, A. C. C; VASCONCELOS, C. B.. Construindo uma proposta pedagógica por meio de materiais manipulativos: Apresentando a fatoração algébrica estudada no LABMATEN/UECE. In: PEREIRA, A. C. C. Educação Matemática no Ceará. Fortaleza: Premius Editora, 2014. Cap. 1. p. 9-27.

PEREIRA, A. C. C.; SAITO, F. A reconstrução do báculo de Petrus Ramus na interface entre história e ensino de matemática. Revista Cocar, Belém, v. 25, n. 13, p.342-372, Jan./Abr., 2019. Disponivel em: https://paginas.uepa.br/seer/index.php/cocar/article/view/2164/1085. Acesso em: 15 dez. 2019.

RODRIGUES, C. S. D. et al.. Pesquisa em educação e bricolagem científica: rigor, multirreferencialidade e interdisciplinaridade. Cadernos de Pesquisa, [s.l.], v. 46, n. 162, p.966-982, dez. 2016. FapUNIFESP (SciELO). Disponível em: <http://dx.doi.org/10.1590/198053143720>. Acesso em: 24 dez. 2019.

RUBTSOV, V. A atividade de aprendizado e os problemas referentes à formação do pensamento teórico dos escolares. In: GARNIER, C. et al.. (Org.). Após Vygotsky e Piaget: perspectivas social e construtivista escolas russa e ocidental. Porto Alegre: Artes Médicas, 1996.

SAITO, F. A reconstrução de antigos instrumentos matemáticos dirigida para a formação de professores. Educação: Teoria e Prática, Rio Claro, v. 29, n. 62, p. 571-589, set/dez, 2019. Disponivel em: https://www.periodicos.rc.biblioteca.unesp.br/index.php/educacao/article/download/14135/1 1298. Acesso em: 15 dez. 2019. 
SAITO, F. História da matemática e suas (re) construções contextuais. São Paulo: Livraria da Física, 2015.

SAITO, F.; DIAS, M. da S. Interface entre história da matemática e ensino: uma atividade desenvolvida com base num documento do século XVI. Ciênc. educ. (Bauru), Bauru, v. 19, n. 1, p. 89-111, 2013. Disponível em:

https://repositorio.unesp.br/bitstream/handle/11449/26487/S151673132013000100007.pdf? sequence=1\&isAllowed=y. Acesso em: 19 dez. 2019.

SOUSA, G. C. de. História da Matemática e Tecnologias de Informação e da Comunicação. In: PEREIRA, A. C. C.; ALVES, F. R. V. (Org.). Ciências e Matemática: investigações no ensino. Curitiba: CRV, 2016. p. 51-66. 